\title{
The Germinlike Protein GLP4 Exhibits Superoxide Dismutase Activity and Is an Important Component of Quantitative Resistance in Wheat and Barley
}

\author{
Anders B. Christensen, ${ }^{1}$ Hans Thordal-Christensen, ${ }^{1}$ Grit Zimmermann, ${ }^{2}$ Torben Gjetting, ${ }^{1}$ Michael F. \\ Lyngkjær, ${ }^{1}$ Robert Dudler, ${ }^{3}$ and Patrick Schweizer ${ }^{2}$ \\ ${ }^{1}$ Risø National Laboratory, Frederiksborgvej 399, P.O. 49, DK-4000 Roskilde, Denmark; ${ }^{2}$ Institute of Plant Genetics and \\ Crop Plant Research, Corrensstrasse 3, D-06466 Gatersleben, Germany; ${ }^{3}$ University of Zürich, Institute of Plant Biology, \\ Zollikerstrasse 107, $\mathrm{CH}-8000$ Zürich, Switzerland
}

Submitted 5 June 2003. Accepted 15 September 2003.

\begin{abstract}
Germinlike proteins (GLP) are encoded in plants by a gene family with proposed functions in plant development and defense. Genes of GLP subfamily 4 of barley (HvGLP4, formerly referred to as $H v O x O L P$ ) and the wheat orthologue TaGLP4 (formerly referred to as TaGLP2a) were previously found to be expressed in pathogen-attacked epidermal tissue of barley and wheat leaves, and the corresponding proteins are proposed to accumulate in the apoplast. Here, the role of $H v G L P 4$ and TaGLP4 in the defense of barley and wheat against Blumeria graminis (DC.) E. O. Speer, the cereal powdery mildew fungus, was examined in an epidermal transient expression system and in transgenic Arabidopsis thaliana plants overexpressing His-tagged HvGLP4. Leaf extracts of transgenic Arabidopsis overexpressing HvGLP4 contained a novel His-tagged protein with superoxide dismutase activity and HvGLP4 epitopes. Transient overexpression of TaGLP4 and $\mathrm{HvGLP4}$ enhanced resistance against $B$. graminis in wheat and barley, whereas transient silencing by RNA interference reduced basal resistance in both cereals. The effect of GLP4 overexpression or silencing was strongly influenced by the genotype of the plant. The data suggest that members of GLP subfamily 4 are components of quantitative resistance in both barley and wheat, acting together with other, as yet unknown, plant components.
\end{abstract}

Additional keywords: RNAi, transgene.

Attack of wheat and barley by Blumeria graminis (DC.) E. O. Speer, the causal agent of cereal powdery mildew and agronomically one of the most important pathogens of both crops, is accompanied by multiple defense responses. These include formation of cell-wall appositions (papillae) at sites of attempted penetration, hypersensitive cell death (HR) of attacked epidermal cells, as well as accumulation of a number of pathogenesis-related (PR) proteins and of low molecularweight components (Schulze-Lefert and Vogel 2000; ThordalChristensen et al. 2000). In many instances of disease resis-

Corresponding author: P. Schweizer; E-mail: schweiz@ipk-gatersleben.de

Current address of A. B. Christensen: Novo Mordisk A/S, DK 2880 Bagsvaerd, Denmark. tance mediated by single major genes of the host ( $R$ genes), the plant response is characterized by HR (Hückelhoven et al. 1999). On the other hand, quantitative or basal disease resistance has been found to be based on efficient papillae as well as on HR, to varying extent (Asher et al. 1983: Kmecl et al. 1995). Basal resistance is probably expressed in all susceptible wheat-Blumeria and barley-Blumeria interactions and defines the extent to which infection attempts fail.

Upon attack of barley and wheat by $B$. graminis or other pathogens, a number of defense-related or PR genes are induced, as in many other plant species (Gregersen et al. 1997; Schweizer et al. 1989). Some of these genes encoding, for instance, chitinases, $\beta$-1,3-glucanases, or thionins may play a role by directly attacking the invading pathogen or by building up new barriers against fungal ingress or spread. For others, the function is still unknown. Since the vast majority, if not all, of the PR genes are known to be induced in all types of incompatible as well as compatible interactions between wheat or barley and B. graminis, the defense-related relevance of these putative downstream effector genes remains unknown in these interactions (Thordal-Christensen et al. 2000).

In barley, the large and poorly understood superfamily of germinlike proteins (GLP) has recently been grouped into five subfamilies (Druka et al. 2002). Members of the barley and wheat GLP4 subfamily ( $H v G L P 4$, formerly referred to as $H v O x O L P$, and $T a G L P 4$, formerly referred to as $T a G L P 2$, respectively) appear to be expressed predominantly in $B$. graminis-attacked leaf epidermal tissue (Schweizer et al. 1999a; Wei et al. 1998). This expression pattern is supported by data-mining in the barley expressed sequence tag (EST) IPK database, in which $44 H v G L P 4$ out of approximately 5,000 EST from pathogen-attacked epidermis compared with one of a total of approximately 106,000 ESTs from 21 other cDNA libraries. The deduced mature peptide sequences of TaGLP4 and HvGLP4 have residues $96 \%$ identical, which is clearly higher than identities between GLP of different subfamilies within one of those species, suggesting that the HvGLP4 and TaGLP4 genes are true orthologues. HvGLP4 has been found to represent a cluster of at least nine duplicated genes (Druka et al. 2002; Wei et al. 1998), and the same may be true for TaGLP4 in wheat, based on EST clustering analysis and hybridization patterns to wheat genomic DNA (data not shown). For convenience, the specific gene subfamily member of barley and wheat used in this study is simply named 
HvGLP4 and TaGLP4, respectively. Both have been found to be induced by $B$. graminis by using gene specific probes of the $5^{\prime}$ or $3^{\prime}$ untranslated region of the corresonding mRNAs (data not shown).

$H v$ GLP4 exists in a heat-stable and sodium dodecyl sulfate (SDS)-resistant oligomeric form (Wei et al. 1998), similar to TaGLP1 (oxalate oxidase). Crystallographic analysis of TaGLP1 has demonstrated a homohexameric structure organized as a trimer of dimers with a molecular mass of approximately $100 \mathrm{kDa}$. While the monomer is stabilized by a single disulfide bond between two cystein residues also present in GLP4, both the dimers and the trimer are stabilized by extensive hydrophobic interactions (Woo et al. 2000). The tight organization of the hexamer presumably accounts for the extreme heat-tolerance, the resistance to SDS, and the proteolytic stability known for GLP (Woo et al. 2000). Some GLP were identified as oxalate oxidases and superoxide dismutases (SOD) (Carter and Thornburg 2000; Woo et al. 2000; Yamahara et al. 1999), $H v$ GLP2 (formerly referred to as $H v$ GLP1) was identified as an extra-cellular nucleotide-sugar pyrophosphatase/ phosphodiesterase (Rodriguez-Lopez et al. 2001), and a wheat GLP closely related to $H v$ GLP2 has recently been described as a serine protease inhibitor (Segarra et al. 2003). Besides known enzymatic activities for some germinlike proteins, data concerning their biological roles in plant development or stress responses are scarce. Only for wheat oxalate oxidase (TaGLP1) are functional data from transgenic plants overexpressing this gene available, and these suggest that the oxalate oxidase protein plays a role in warding off oxalate-producing pathogens as well as herbivores (Donaldson et al. 2001; Liang et al. 2001; Ramputh et al. 2002).

In order to obtain functional data on defense-related genes in wheat and barley more rapidly than would be possible based on transgenic plants, a transient assay system was developed for overexpression of host or foreign genes as well as for gene silencing by RNA interference (RNAi) in single epidermal cells of wheat and barley (Nielsen et al. 1999; Schweizer et al. $1999 \mathrm{~b}, 2000)$. The transient assay has proven valuable for revealing novel gene function in race-specific as well as racenonspecific interactions between barley and B. graminis f. sp.
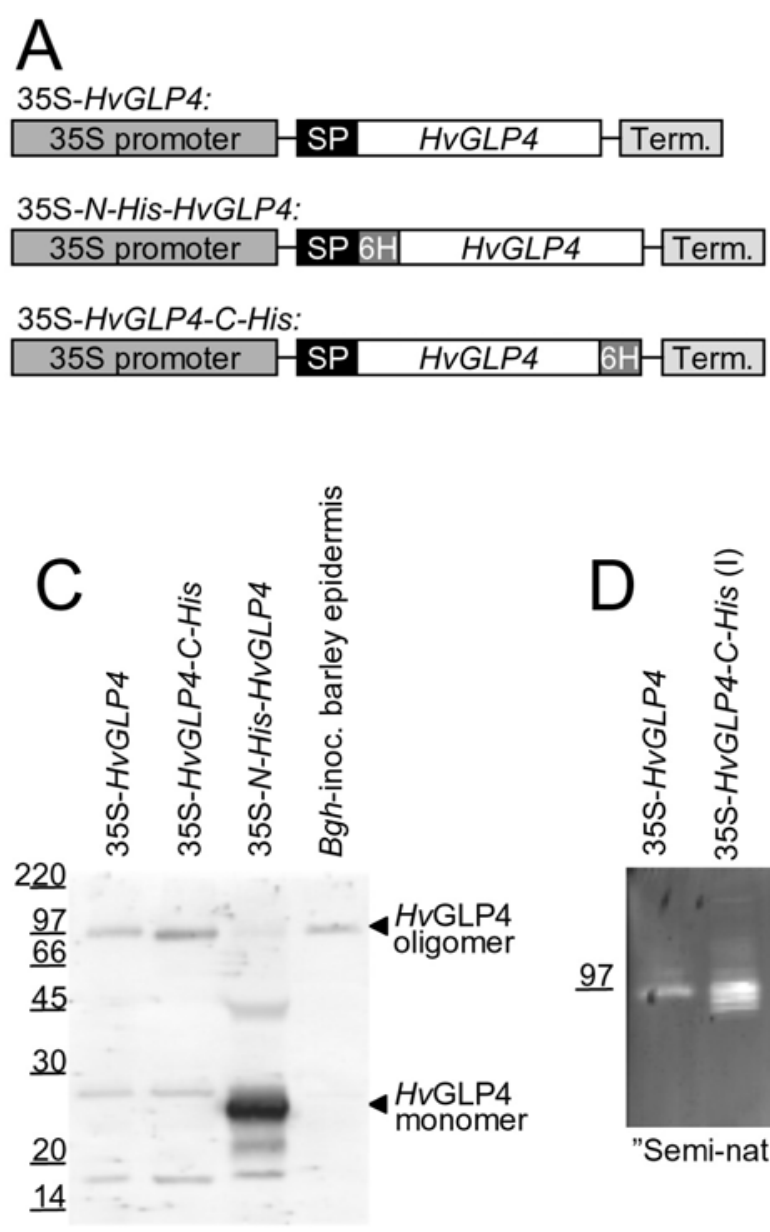

"Semi-native"/Immunoblot
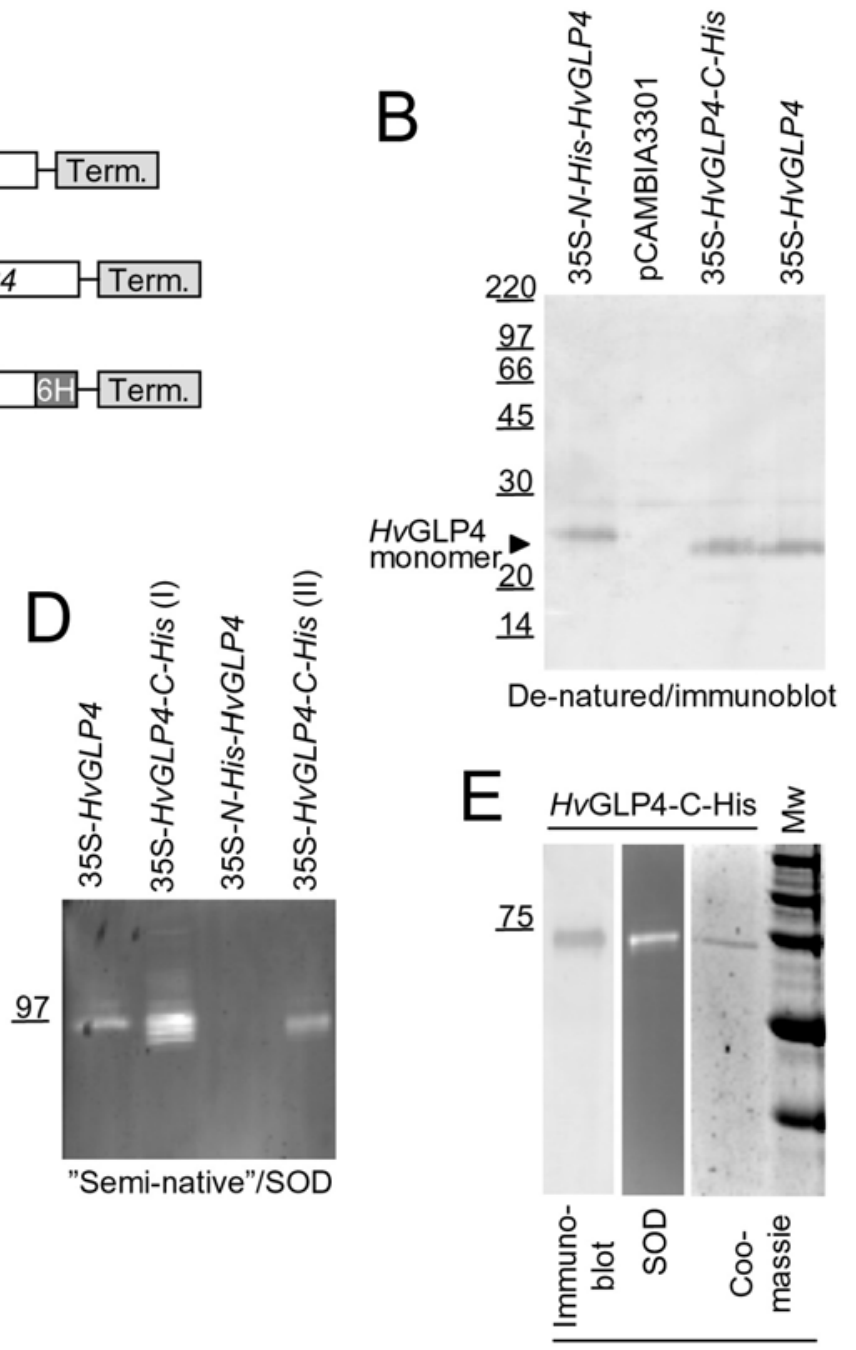

"Semi-native"

Fig. 1. The barley $H \nu$ GLP4 has superoxide dismutase (SOD) activity. A, Wild-type, N-, and C-terminally His-tagged versions of $H v$ GLP4 were expressed ectopically in Arabidopsis thaliana (Columbia). SP = wild-type signal peptide of $H \nu \mathrm{GLP} 4 ; 6 \mathrm{H}=$ six histidine residues. B, Immunoblot, using an $H \nu \mathrm{GLP} 4$ specific antiserum, of denaturing sodium dodecyl sulfate-polyacrylamide gel electrophoresis (SDS-PAGE) gels shows the monomers of the three versions of $H v \mathrm{GLP} 4$ in crude A. thaliana leaf extract. Extract of $A$. thaliana transformed with the pCAMBIA3301 vector served as a negative control. C, Immunoblot, using an $H v$ GLP4-specific antiserum, of seminative SDS-PAGE gels loaded with crude leaf extract samples, which have not been boiled with a reducing agent prior to loading. D, In-gel SOD assay. I and II denote extracts from independent transgenic lines. E, Seminative SDS-PAGE of recombinant C-terminally His-tagged $H v G L P 4$, purified from transgenic A. thaliana by Ni-affinity chromatography, loaded onto three lanes, which were analyzed separately: as in C, D, and by Coomassie total protein staining. Numbers at the left borders of the gels or blots indicate molecular masses in kDa. 
hordei (Azevedo et al. 2002; Hückelhoven et al. 2003; Kim et al. 2002; Zhou et al. 2001). Using this assay, enhanced resistance against $B$. graminis $\mathrm{f}$. sp. tritici of wheat epidermal cells transiently expressing TaGLP1 (oxalate oxidase) and TaGLP4 was obtained, suggesting that germinlike proteins play a role in pathogen defense of cereals (Schweizer et al. 1999a).

The race-nonspecific cell-wall penetration resistance exerted by leaf epidermal cells against the initial attack by many fungi is found to be accompanied by the accumulation of $\mathrm{H}_{2} \mathrm{O}_{2}$ in several plants (Heath 2001; Mellersh et al. 2002; ThordalChristensen et al. 1997). Penetration resistance is believed to be the result of de novo development of a local cell wall fortification consisting of a number of structural polymers that become crosslinked by a proposed $\mathrm{H}_{2} \mathrm{O}_{2}$-driven process. In cowpea, tomato, and plantain, removal of the penetration-associated $\mathrm{H}_{2} \mathrm{O}_{2}$, using catalase, leads to susceptibility, suggesting that this $\mathrm{H}_{2} \mathrm{O}_{2}$ has a role in resistance (Mellersh et al. 2002). In barley and wheat, the temporal and spatial expression pattern of GLP4, together with sequence similarity to the $\mathrm{H}_{2} \mathrm{O}_{2}$-generating oxalate oxidase (GLP1), led to speculations that this gene may be responsible for producing the penetration-associated $\mathrm{H}_{2} \mathrm{O}_{2}$ (Schweizer et al. 1999a; Wei et al. 1998). Here, we identify $H v$ GLP4 as a functional SOD, and by transient overexpres-

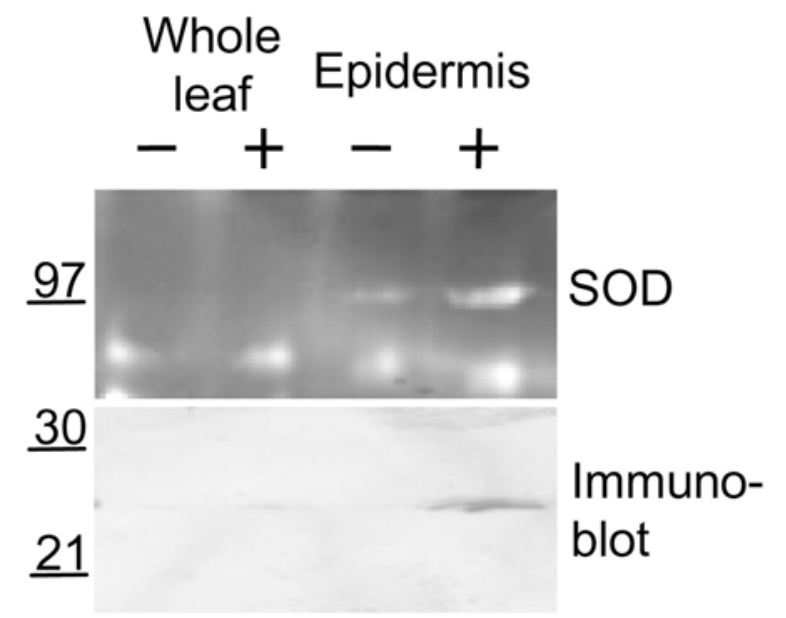

Fig. 2. Blumeria graminis f. sp. hordei-induced superoxide dismutase in the barley leaf epidermis. SOD, In-gel assay of crude extracts of wholeleaf and epidermal tissue of cv. Ingrid, respectively, prepared $24 \mathrm{~h}$ postinoculation with $B$. graminis f. sp. hordei $(+)$. $-=$ noninoculated controls. The loaded samples were not boiled with reducing agent (seminative). Immunoblot, blot of a seminative gel developed with $H v$ GLP4-specific antiserum.

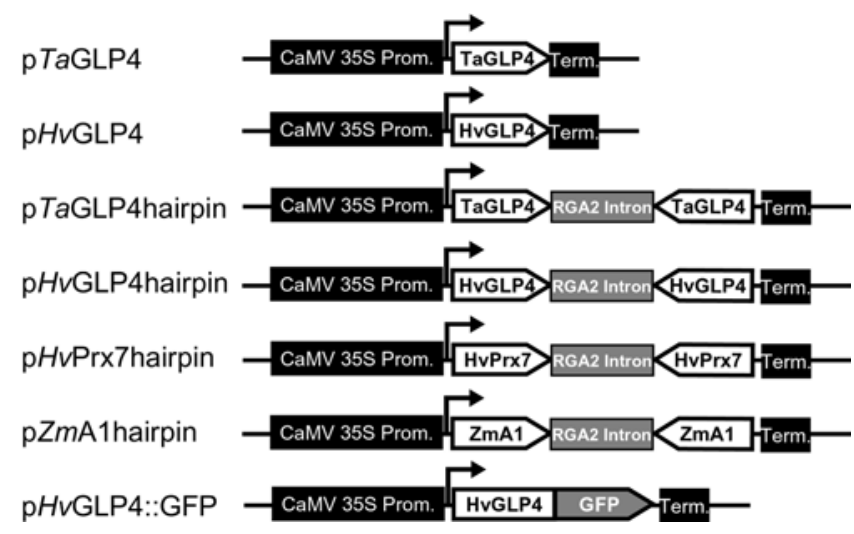

Fig. 3. Constructs used for transient overexpression or RNA interference in wheat and barley leaf segments. sion and RNA interference experiments with $H v G L P 4$ and TaGLP4, we provide evidence that GLP4 contributes to disease resistance in wheat and barley.

\section{RESULTS}

HvGLP4 possesses SOD activity.

In order to characterize $H \nu$ GLP4 biochemically, we expressed this barley protein ectopically in Arabidopsis thaliana. Three gene constructs, all for $35 \mathrm{~S}$ promoter-driven constitutive expression of $H v G L P 4$, were generated: p35S$H v G L P 4$ for the wild-type barley protein and p35S-N-His$H v G L P 4$ plus p35S-HvGLP4-C-His for $\mathrm{N}$ - and C-terminal histidine (His)-tagged versions of the protein, respectively (Fig. 1A). HvGLP4 has a predicted signal peptide directing the protein into the default secretory pathway. Therefore, the $\mathrm{N}$-terminal His-tag was introduced to two amino acids Cterminal of the predicted signal peptide cleavage site. Transgenic plants with each of the three constructs expressed HvGLP4 protein, as demonstrated by immuno-blotting of protein extracts using a $H v$ GLP4-specific antiserum (Fig. 1B and $\mathrm{C}$ ). $H v \mathrm{GLP} 4$, like other GLP, exists in an oligomeric, SDS-resistant form, and this oligomer can be revealed if run in a "seminative" way, i.e., on SDS gels without prior boiling with a reducing agent (Wei et al. 1998). After denaturing SDS-polyacrylamide gel electrophoresis (PAGE), the gel blot showed the N-terminally His-tagged monomers to be approximately $2 \mathrm{kDa}$ larger than the wild-type and C-terminally His-tagged proteins (Fig. 1B), suggesting that the signal peptide has not been cleaved from the $\mathrm{N}$-terminally His-tagged protein. This most likely explains why the oligomeric form of the N-terminally His-tagged protein did not assemble, as shown on the blot of the seminative gel (Fig. 1C). However, oligomers of the wild-type and the C-terminally His-tagged protein migrated to similar positions as the protein extracted from barley epidermal tissue (Fig. 1C).

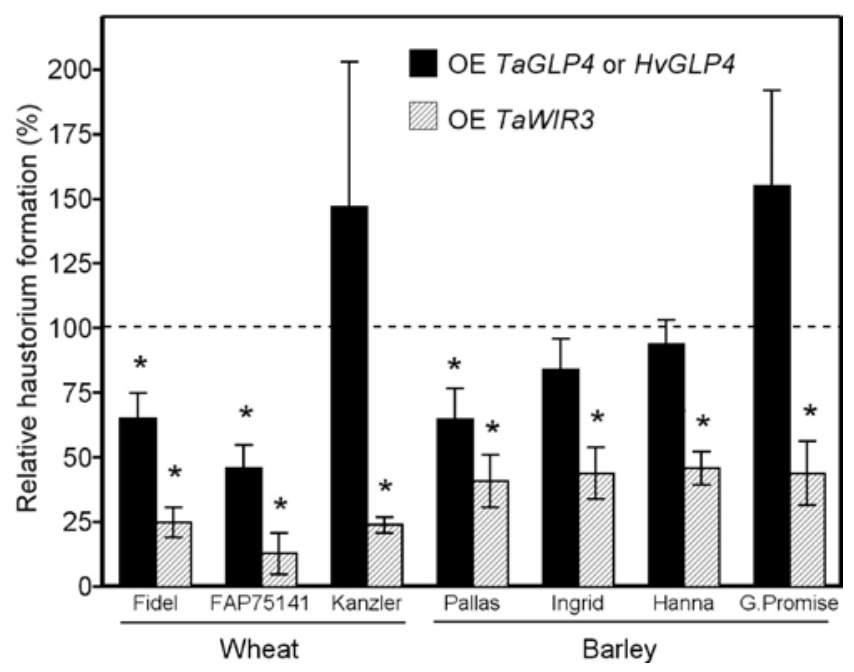

Fig. 4. Transient overexpression of GLP4 enhances basal disease resistance in wheat and barley. Barley HvGLP4 cDNA (construct $\mathrm{p} H \nu \mathrm{GLP} 4)$ was transiently overexpressed, followed by inoculation with $B$. graminis and scoring of the interaction phenotype $40 \mathrm{~h}$ postinoculation. Bombarded, successfully transformed cells were detected by $\beta$-glucuronidase-staining. As an exception, wheat cv. FAP75141 was bombarded with TaGLP4 (construct pTaGLP4) and not with $H v G L P 4$. As positive control, the WIR3 gene from wheat, encoding a putative peroxidase, was overexpressed (pWIR3, Schweizer et al. 1999b). Mean \pm SE of at least four independent bombardments, with a total of approximately 2,000 observed interactions per cultivar and transgene. ${ }^{*}=$ statistically significant (one-sample $t$-test against control value; $P<0.05)$. 
Inspired by reports of SOD activity of other GLP (Carter and Thornburg 2000; Woo et al. 2000; Yamahara et al. 1999), the heterologously expressed $H v$ GLP4 proteins were subjected to an in-gel SOD assay. Crude extracts of plants producing the wild-type or the C-terminally His-tagged HvGLP4 showed a catalytically active protein of approximately $100 \mathrm{kDa}$ (Fig. 1D). Meanwhile, extracts of plants expressing the N-terminally His-tagged $H v$ GLP4 and of control plants transformed with an empty vector construct showed no activity (Fig. 1D and data not shown, respectively). In plants expressing oligomeric forms of $H v G L P 4$, SOD activities were occasionally seen in several bands in the gel (Fig. 1D). Affinity purification on a Ni-NTA column of the C-terminally His-tagged HvGLP4 directly from desalted, crude protein extracts was not successful. However, denaturation in $8 \mathrm{M}$ urea allowed it to bind to the column. Following a gradual removal of the urea on the column using a 1-mM $\mathrm{Mn}^{++}$buffer, an apparently pure protein oligomer was eluted, which had a mass of $72 \mathrm{kDa}$ on the seminative gel. The same protein was recognized by the HvGLP4-specific antibody and exhibited SOD activity (Fig. 1E). On a denaturing gel, the protein had a mass of approximately $25 \mathrm{kDa}$ (data not shown). The cause of the difference in size of the protein before and after affinity chromatography is currently not understood. GLP hexamers are believed to be organized in a very tight structure as a trimer of dimers stabilized by hydrophobic interactions (Woo et al. 2000). However, renaturation of the protein on the column may favor formation of a form that differs from the one assembled in the plant. Nevertheless, this experiment shows that $H v$ GLP4 has SOD activity and requires $\mathrm{Mn}^{++}$, as omission of $\mathrm{Mn}^{++}$in the buffer during renaturation resulted in loss of SOD activity (data not shown).

The transgenic Arabidopsis lines expressing active $H v$ GLP4 SOD under the control of the constitutive $35 \mathrm{~S}$ promoter did not

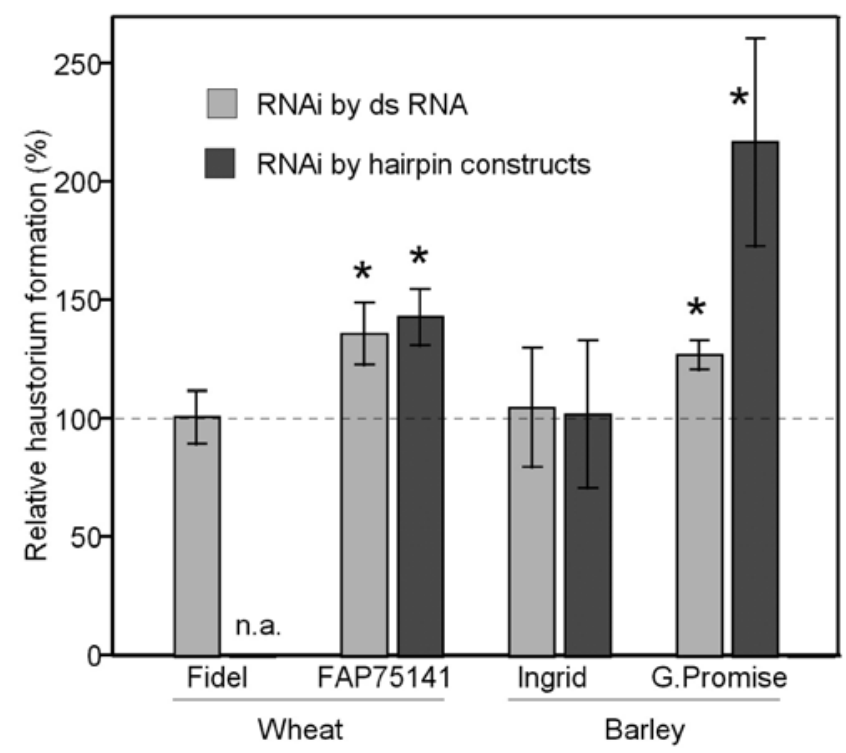

Fig. 5. Transient silencing of GLP4 by RNA interference (RNAi) induces hypersusceptibility to Blumeria graminis in wheat and barley. RNAi was induced by bombarding wheat and barley leaves with tungsten and gold particles, respectively, which were coated with double-stranded (ds)RNA or with hairpin constructs. Wheat was bombarded with dsRNA of TaGLP4 or with construct pTaGLP4hairpin, whereas barley was bombarded with dsRNA of $H v G L P 4$ or with $\mathrm{pH} v \mathrm{GLP} 4$ hairpin. Note that barley leaves transformed with the $\mathrm{pH} v$ GLP4hairpin construct were challenge-inoculated $48 \mathrm{~h}$ postbombardment, whereas all other leaves were challenge-inoculated $4 \mathrm{~h}$ postbombardment. Mean \pm SE of at least five independent bombardments, with a total of approximately 1,200 observed interactions per cultivar and transgene. $*=$ statistically significant (one-sample $t$-test against control value; $P<0.05$ ). exhibit an altered morphological phenotype. The susceptibility to Erysiphe cichoracearum, causing powdery mildew on Arabidopsis, was also not affected (data not shown).

Knowing that the barley epidermal $B$. graminis f. sp. hordeiinduced $H v$ GLP4 possesses SOD activity, we wanted to confirm this response at the enzyme level. Figure 2 shows that, within the barley leaf, a SOD enzyme of approximately 100 $\mathrm{kDa}$ is concentrated in the epidermis and this activity increases in response to powdery mildew attack. The response is paralleled by an increase in abundance of a protein of the same size that is recognized by the $H v$ GLP4-specific antibody.

\section{GLP4 is important for quantitative resistance in wheat and barley.}

Using a recently developed transient assay system (Schweizer et al. 1999b; 2000), HvGLP4 and TaGLP4 were overexpressed as well as silenced by RNAi in a panel of susceptible wheat and barley cultivars. Leaf segments were bombarded with different constructs, as shown in Figure 3. Overexpression of HvGLP4 and of TaGLP4 significantly reduced the frequency of fungal haustoria formation in two of three tested wheat and in one of four tested barley cultivars (Fig. 4), whereas overexpression of TaWIR3 encoding a putative peroxidase reduced haustorium formation in all tested lines. Overexpression of HvGLP4 and of TaGLP4 in wheat cv. Fidel reduced haustorium formation to (65 $\pm 10) \%$ and $(56 \pm 6) \%$ of control, respectively, indicating that both transgenes have a similar resistance-enhancing potential (Schweizer et al. 1999a) (Fig. 4). The trend for enhanced relative haustorium formation in wheat cv. Kanzler and barley cv. Golden Promise overexpressing GLP4 genes was statistically not significant and will not be discussed further. Silencing of the TaGLP4 gene in wheat and the $H v G L P 4$ gene in barley by RNAi revealed enhanced haustorium formation of $B$. graminis f. sp. tritici and $B$. graminis f. sp. hordei on one of the two tested wheat and barley cultivars, respectively (Fig. 5). In wheat cv. FAP75141 and in barley cv. Golden Promise, the effect was observed irrespective of whether RNAi was induced by microprojectile bombardment with double-stranded (ds)RNA-coated particles or by particles coated with RNAi constructs, giving rise to spliced hairpin dsRNA in vivo. Prolongation of the time between bombardment and challenge-inoculation considerably enhanced basal resistance in wheat, which prompted us to challenge-inoculate leaves as early as $4 \mathrm{~h}$ postbombardment. In barley, no effect of pHvGLP4 hairpin was observed when leaves were challenge-inoculated $4 \mathrm{~h}$ after bombardment (data not shown). Therefore, the incubation time between bombardment and challenge-inoculation was prolonged to $48 \mathrm{~h}$. This was possible because there was no dramatic increase in basal resistance of bombarded barley leaves over time, in contrast to wheat. Indeed, under these experimental conditions, there was a strong RNAi effect found in barley cv. Golden Promise (Fig. 5). Based on these results, it may be speculated that, in both wheat and barley bombarded with hairpin constructs, the RNAi effect took longer to become fully established than the available time between bombardment and attempted fungal penetration upon early challenge-inoculation $(4 \mathrm{~h})$. In barley, this may have resulted in no detectable effect, whereas in

Table 1. HvGLP4 double-stranded (ds)RNA specifically interferes with the accumulation of $H v$ GLP4::GFP fusion protein

\begin{tabular}{lcc}
\hline & \multicolumn{2}{c}{ Fluorescent cells/shot } \\
\cline { 2 - 3 } Constructs & Golden Promise & Ingrid \\
\hline pHvPrx7 hairpin + pHvGLP4::GFP & $370^{\mathrm{a}}$ & 342 \\
pHvGLP4 hairpin + pHvGLP4::GFP & 9 & 2 \\
pHvPrx7 hairpin + pGFP & 105 & 336 \\
pHvGLP4 hairpin + pGFP & 264 & 270 \\
\hline
\end{tabular}

${ }^{a}$ Mean values from two independent bombardment experiments. 
wheat, it resulted in a weaker effect, compared with the one in barley that was challenge-inoculated $48 \mathrm{~h}$ after bombardment. By contrast, the RNAi effect of directly bombarded dsRNA may have been faster compared with hairpin constructs because no transcription and splicing was required within transformed cells but, also, more transient because it depended on limiting initial amounts of active principle (dsRNA) that reached the target cells (Schweizer et al. 2000).

The efficiency of RNAi was demonstrated in an experiment in which barley was cobombarded with a HvGLP4::GFP fusion construct plus the HvGLP4 RNAi construct (Fig. 3 and Table 1). As control, an RNAi construct of barley peroxidase Prx7 was cobombarded with the HvGLP4::GFP fusion construct. The HvGLP4 RNAi construct inhibited the accumulation of $H v$ GLP4::GFP fusion protein with an efficiency of approximately $98 \%$ in both cvs. tested (Ingrid and Golden Promise). The RNAi effect was gene specific, as the $\mathrm{pH} v \mathrm{GLP} 4$ hairpin RNAi construct had no inhibitory effect on the accumulation of green fluorescent protein (GFP) alone. These results indicate that the absence of an effect of HvGLP4 RNAi on the interaction of barley cv. Ingrid with $B$. graminis f. sp. hordei was probably not due to a reduced RNAi capacity, as compared with cv. Golden Promise.

In an attempt to correlate GLP4 expression to the observed effects of GLP4 overexpression or silencing, we carried out Northern blot experiments in the four lines that were also used for RNAi studies (Fig. 6). The expectation might be that weak expressers would respond to GLP4 overexpression with enhanced resistance, whereas strong expressers would respond to GLP4 RNAi with enhanced susceptibility. Indeed, both lines showing enhanced susceptibility upon GLP4 RNAi expressed the corresponding gene or genes to a high extent. However, in the case of the observed effect of TaGLP4 overexpression in wheat cv. FAP75141 and the absence of an RNAi effect in barley cv. Ingrid, the expectation was not met by the results of the expression analysis.

\section{HvGLP4 may not be involved in localized}

$\mathrm{H}_{2} \mathrm{O}_{2}$ accumulation at sites of attempted penetration.

$\mathrm{H \nu}$ GLP4 has been identified here as an extracellular SOD (Fig. 1), opening the possibility that this protein might be responsible for the localized microburst of $\mathrm{H}_{2} \mathrm{O}_{2}$ by converting

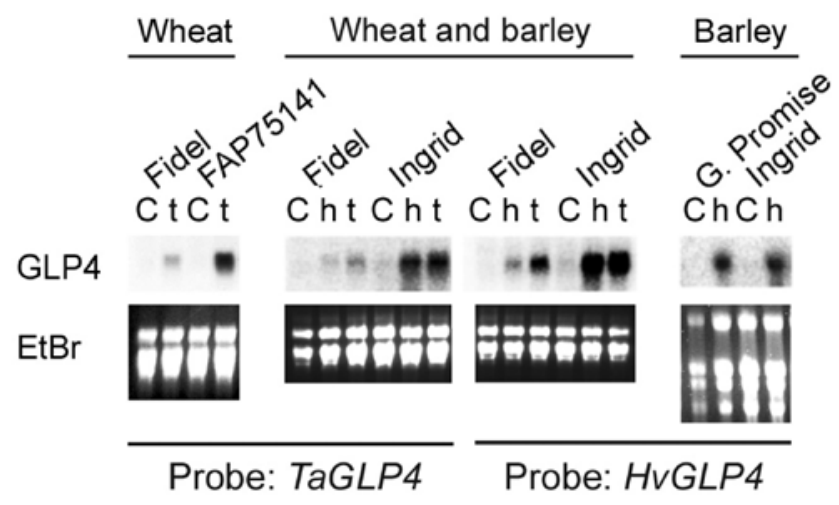

Fig. 6. Comparison of GLP4 RNA abundance in wheat and barley genotypes. RNA was isolated from control (C) or inoculated leaves $(24 \mathrm{~h}$ postinoculation), and blots of wheat and barley RNA were hybridized with probe TaGLP4 and $H v G L P 4$, respectively. The comparison of transcript abundance between wheat and barley was done by inoculating plants with $B$. graminis f. sp. hordei (h) or with $B$. graminis f. sp. tritici (t) and by probing parallel blots with $T a G L P 4$ or with $H v G L P 4$. Ethidium bromide-stained gels prior to blotting are shown below the blots. RNA from genotype pairs to be compared comes from parallel inoculation experiments with comparable inoculum densities (around 30 to 50 conidia $\mathrm{mm}^{-2}$ ).
$\mathrm{O}_{2} \cdot{ }^{--}$radicals, which are produced by e.g., NAD $(\mathrm{P}) \mathrm{H}$ oxidases, to $\mathrm{H}_{2} \mathrm{O}_{2}$ at sites of attempted penetration by primary or appressorial germ tubes of B. graminis f. sp. hordei or B. graminis $\mathrm{f}$. sp. tritici. If this hypothesis is true, then RNAi targeted to $H v G L P 4$ in bombarded cells should prevent or at least significantly reduce the localized $\mathrm{H}_{2} \mathrm{O}_{2}$ microburst, as detected by the oxidation of 3,3-diaminobenzidine (DAB) in bombarded leaves previously loaded with DAB. For this purpose, DAB oxidation associated with attempted appressorial penetration was assessed in cells transformed with the $\beta$-glucuronidase (GUS) reporter gene together with the RNAi control construct pZmAlhairpin (targeting the maize $A 1$ gene) or together with $\mathrm{pHvGLP} 4$ hairpin. Figure 7 shows that RNAi of HvGLP4 in barley cv. Golden Promise, which showed strong hypersusceptibility upon silencing of this gene, did not significantly reduce the percentage of transformed cells with detectable DAB oxidation. The same was true in neighboring, nontransformed cells, indicating that the amounts of DAB that reached the transformed leaf areas and that directly influenced staining intensities were comparable between control and test leaves bombarded with pZmA1 hairpin and $\mathrm{pH}$ GLP4hairpin, respectively.

\section{DISCUSSION}

The identification of $H v$ GLP4 as functional Mn-SOD puts this barley epidermis-expressed protein together with a group of GLP with known SOD activity (Carter and Thornburg 2000; Woo et al. 2000; Yamahara et al. 1999). These GLP-SOD are unrelated to previously characterized intracellular plant SOD (Alscher et al. 2002). Plant SOD, proposed to be involved in scavenging of reactive oxygen species together with catalase but also generating $\mathrm{H}_{2} \mathrm{O}_{2}$, have been found to be up-regulated

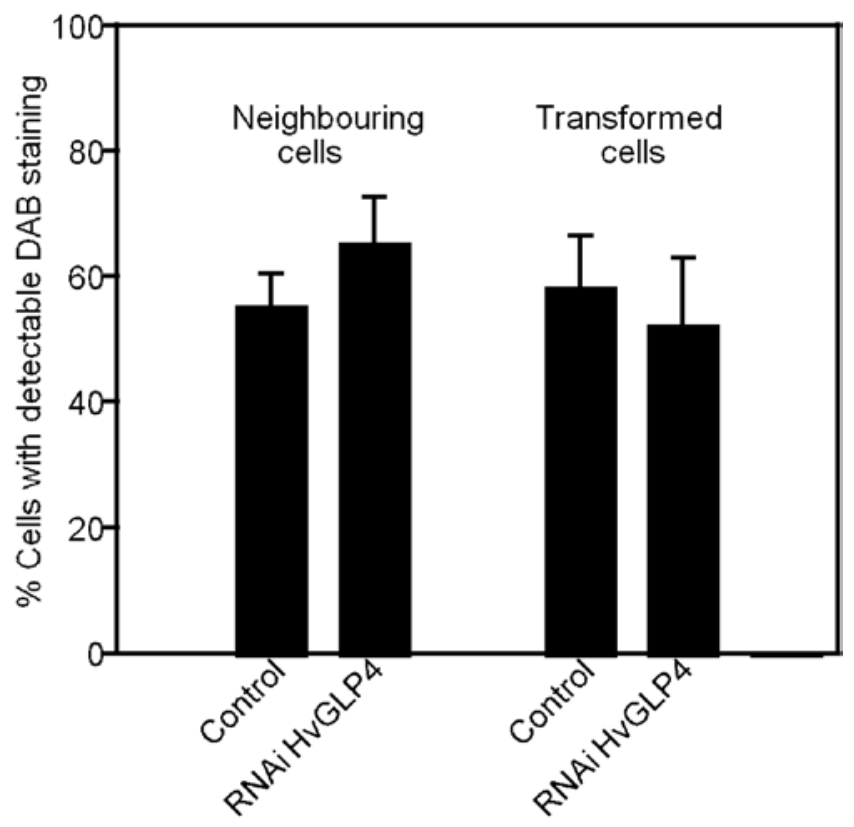

Fig. 7. RNA interference (RNAi) of $H v G L P 4$ does not reduce local accumulation of $\mathrm{H}_{2} \mathrm{O}_{2}$ underneath fungal appressoria. Leaves bombarded with $\mathrm{pH} v \mathrm{GLP} 4$ hairpin were challenge-inoculated with $B$. graminis f. sp. hordei and were loaded with 3,3-diaminobenzidine (DAB) from 16 to 24 $\mathrm{h}$ postinoculation, followed by $\beta$-glucuronidase (GUS)-staining and microscopic inspection of DAB-staining underneath appressoria in GUSstained cells. Control leaves were bombarded with an RNAi construct directed against the $A 1$ gene of maize. As additional control, DABstaining underneath appressoria in cells immediately adjacent to GUSstained cells attacked by Blumeria spp. was scored. Mean \pm SE from four independent experiments. 
in incompatible plant-pathogen interactions (Babitha et al. 2002; Delledonne et al. 2001; Gay and Tuzon 2000). Some of these are intracellular SOD (Delledonne et al. 2001), but often, the SOD type is not analyzed further. The presence of an $\mathrm{N}$ terminal signal peptide suggests $H v$ GLP4 to be extracellular. Based on this and the expression patterns of HvGLP4 and of the wheat orthologue TaGLP4, we speculated that this SOD is responsible for the localized $\mathrm{H}_{2} \mathrm{O}_{2}$ production that is a general response observed at the site of penetration in barley and wheat attacked by powdery mildew (Schweizer et al. 1999a; ThordalChristensen et al. 1997). The SOD substrate, the superoxide anion, might be produced by NADPH oxidase, an enzyme reported to be activated upon pathogen attack (Keller et al. 1998; Sagi and Fluhr 2001; Yoshioka et al. 2001). The functional data from overexpression and RNAi of HvGLP4 and TaGLP4 do support a role of these germinlike proteins in quantitative resistance of cereals against $B$. graminis, although the importance of SOD enzymatic activity in the plant-pathogen interactions studied here remains open.

The resistance-enhancing effect of HvGLP4 overexpression and the hypersusceptibility-inducing effect of TaGLP4 and $H v G L P 4$ silencing was genotype dependent, in contrast to the resistance-enhancing effect of WIR3 overexpression. This suggests a complex mode of action of GLP4, requiring one or several other host components that might be more or less limiting in a genotype-dependent manner. The fact that, in one of the strong GLP4 expressers, cv. FAP75141 (Fig. 6), overexpression as well as silencing affected resistance, whereas in the other, cv. Ingrid, neither overexpression nor RNAi had an effect also argues for a complex situation involving not just GLP4 protein. Theoretically, genotype dependence of the GLP4 effect might have reflected different expression levels of individual members of the GLP4 subfamiliy in the different wheat and barley cvs. together with incomplete silencing of the whole subfamily of approximately nine genes by the hairpin constructs used. However, this appears unlikely for the following reasons. First, the chosen hairpin constructs were targeted against strongly expressed subfamily members (formerly referred to as HvOxOLP and TaGLP2a, respectively). Second, nucleotide-sequence identity in the coding region targeted by the RNAi constructs was found to be higher than $90 \%$ among subfamily members (G. Zimmermann and P. Schweizer, unpublished data). This degree of sequence similarity was found to be sufficient for efficient silencing by RNAi, as revealed by cross-silencing experiments of HvMlo in barley by a hairpin construct targeted against TaMlo (Elliott et al. 2002; P. Schweizer, unpublished data). On the other hand, the effect of WIR3 overexpression was not dependent on host genotype, demonstrating the general competence of all tested cvs. to respond to transgene expression with enhanced resistance.

We tried to answer the question of whether the SOD activity of HvGLP4 is directly responsible for localized $\mathrm{H}_{2} \mathrm{O}_{2}$ formation at sites of attempted penetration. For this purpose, we analyzed localized DAB oxidation in bombarded and $B$. graminis f. sp. hordei-attacked, epidermal cells with silenced HvGLP4 by using the DAB-uptake method of Thordal-Christensen and associates (1997). For these experiments, we used cv. Golden Promise, which showed strong hypersusceptibility upon RNAi of HvGLP4. However, RNAi of HvGLP4 did not significantly reduce the fraction of cells with detectable localized DAB oxidation at sites of attempted fungal penetration, compared with control cells that expressed an RNAi construct targeted against the maize $A l$ gene. These experiments suggest that there may exist one or more GLP4 (SOD)-independent mechanisms of $\mathrm{H}_{2} \mathrm{O}_{2}$ production in barley epidermis cells attacked by Blumeria spp. Production of $\mathrm{H}_{2} \mathrm{O}_{2}$ due to residual $\mathrm{HvGLP} 4$ expression in cells bombarded with the HvGLP4 RNAi construct appears unlikely, because the same construct silenced cobombarded $H v G L P 4:: G F P$ very efficiently. Moreover, basal levels of $H v G L P 4$ expression in the material used for the RNAi experiments usually was very low (Fig. 6), which makes it unlikely that the residual DAB oxidation was due to preformed not-yet-turned-over $H v$ GLP4 protein in cell walls. Most importantly, although the fraction of transformed cells with detectable DAB oxidation did not decline in cells with silenced HvGLP4, there was induced hypersusceptibility. This suggests that the resistance-enhancing effect of HvGLP4 was not dependent on its contribution to localized $\mathrm{H}_{2} \mathrm{O}_{2}$ accumulation as reflected by DAB oxidation. Extracellular peroxidases have recently been identified as alternative candidates for the production of $\mathrm{H}_{2} \mathrm{O}_{2}$ (Bolwell et al. 2002). Moreover, in several plantpathogen interactions, localized DAB oxidation was found to occur independently from transcription or translation (Mellersh et al. 2002), which argues against an inducible component like $H v$ GLP4 as sole source of $\mathrm{H}_{2} \mathrm{O}_{2}$ and suggests a second mechanism based on preformed peroxidase. However, in contrast to the documented existence in barley epidermis of preformed peroxidase activity capable of oxidizing DAB at the expense of $\mathrm{H}_{2} \mathrm{O}_{2}$ (Thordal-Christensen et al. 1997), no information on extracellular peroxidases capable of generating $\mathrm{H}_{2} \mathrm{O}_{2}$ is currently available in barley.

If GLP4 proteins are not primarily involved in localized $\mathrm{H}_{2} \mathrm{O}_{2}$ accumulation in epidermis cells attacked by Blumeria spp., what might be the mechanism of their resistance-enhancing effect? Some GLP have been found to be associated with the cell wall (Bernier and Berna 2001). Upon stress treatments of barley, $H v \mathrm{GLP} 2$ (formerly referred to as $H v \mathrm{GLP} 1$ ) became insolubilized (Vallelian et al. 1998), and covalent cross-linking of transiently expressed oxalate oxidase (TaGLP1) at sites of attempted penetration by B. graminis f. sp. tritici was observed in wheat (Schweizer et al. 1999a). Moreover, domain-swap experiments between TaGLP1 and HvGLP2 resulting in proteins that had lost oxalate-oxidase activity but still retained at least partially their resistance-enhancing potential, support a structural role of TaGLP1 (Schweizer et al. 1999a). Therefore, GLP might also have a function as structural cell-wall proteins reenforcing the extracellular macromolecular network in response to attempted fungal ingress. HvGLP4 has been found to be expressed in several stressed and unstressed tissues of barley (G. Zimmermann and P. Schweizer, unpublished data). Therefore, it may be speculated that the SOD activity of the protein or proteins is essential for their function in one or several tissues other than leaf epidermis or in stresses imposed onto leaves other than attack by Blumeria graminis. Further studies on structure-function relationships in proteins of the GLP4 subfamily, including mutated forms without SOD activity, as well as the search for a putative $\mathrm{H}_{2} \mathrm{O}_{2}$-generating peroxidase and cross-linking substrates will be required to further elucidate the basis of penetration resistance in cereals.

\section{MATERIALS AND METHODS}

\section{Plants and fungi.}

A. thaliana ecotype Columbia-0 was transformed according to the floral dip method of Clough and Bent (1998). Transgenic lines were selected on soil after spraying with Basta (Bayer, Leverkusen, Germany).

Wheat seedlings and Blumeria graminis DC. Speer f. sp. tritici Em. Marchal were grown and maintained as described (Schweizer et al. 1999b). Barley seedlings were grown in a growth chamber (16-h light from metal halogen lamps; 8-h dark, $70 \%$ relative humidity, $18^{\circ} \mathrm{C}$ constant temperature). B. graminis f. sp. hordei (Isolate 4.8 carrying AvrMla9) was maintained by weekly transfer to fresh barley cv. Golden Promise. 


\section{Plasmids.}

Three constructs for $H v$ GLP4 overexpression in A. thaliana (Fig. 1) were generated in a modified pCAMBIA3301 binary expression vector (CAMBIA, Canberra, Australia). This vector confers expression under control of the cauliflower mosaic virus $35 \mathrm{~S}$ promoter and has a Bar gene for plant selection. The $\mathrm{N}-\mathrm{His}-\mathrm{HvGLP4}$ coding sequence was prepared by amplifying the barley HvGLP4 cDNA pBH6-903 (accession number X93171) in pBluescript (Stratagene, La Jolla, CA, U.S.A.), using the 75-mer primer 5'-AGCGTTGGTCTCATGGCAGG CAACTTCCTCCGACCCTCATCATCATCATCATCATGAC CCTAGCCCACTCCAAGA-3' and the vector primer 5'-CAC ACAGGAAACAGCTATGACC-3', followed by trimming of the fragment using $B s a \mathrm{I}$ and EcoRV and recloning of the fragment back into pBH6-903 digested with the same enzymes. The 75-mer primer introduced six histidine residues, two amino acids $\mathrm{C}$-terminal of the predicted signal peptide cleavage-site. The HvGLP4-C-His coding sequence was prepared by amplifying the barley cDNA pBH6-903 using the 55-mer primer 5' CACCCAACACGTGACTTAATGATGATGATGATGATGAT TGTGGTTGTTCTCCCAG-3' and the vector primer 5'-CGCT CTAGAACTAGTGGATC-3'. The 55-mer primer introduced six histidine residues at the $\mathrm{C}$-terminal end of the protein. The fragment was cloned into the pCRscript vector (Stratagene). In order to modify pCAMBIA3301, its GUS start codon (ATG) was destroyed by an NcoI digest followed by a treatment with Taq polymerase in the presence of only dCTP. Subsequently, the GUS-coding region was removed by a $P m l \mathrm{I} / B g l \mathrm{II}$ digest that left the nos terminator intact. The HvGLP4 coding sequence in the pBH6-903 cDNA and the N-His-HvGLP4 and $H v G L P 4-C$-His coding sequences were all cut from their vectors using $B a m \mathrm{HI}$ and $P m l \mathrm{I}$ and were ligated into the $B g l I I / P m l I$-digested modified pCAMBIA3301 vector.

Constructs for transient overexpression and RNAi studies (Fig. 3) were based on a wheat TaGLP4 cDNA clone (accession number AJ237942) and the barley HvGLP4 cDNA clone pBH6-903. Expression construct pTaGLP4 (35S Prom $_{\text {-TaGLP4- }}$ $35 \mathrm{~S}_{\text {term }}$; formerly referred to as pGLP2) (Schweizer et al. $1999 \mathrm{a})$ and $\mathrm{pH} v \mathrm{GLP} 4\left(35 \mathrm{~S}_{\text {Prom }}-H \nu \mathrm{GLP} 4-35 \mathrm{~S}_{\text {term }}\right)$ was used for GLP4 overexpression in wheat and barley. Construct $\mathrm{pH} v \mathrm{GLP} 4$ was obtained by cloning a SalI/PstI fragment of pBH6-903 between the SalI/PstI sites of the expression vector pGY1 (Schweizer et al. 1999b). The TaGLP4 cDNA clone (accession number AJ237942) and pPcrGLP4 were used for in vitro synthesis of dsRNA (Schweizer et al. 2000) and contained TaGLP4 near full-length cDNA in pBluescript (Stratagene) and a 630-bp polymerase chain reaction (PCR) fragment encompassing the open reading frame of $H v G L P 4$ in pCR-TOPOII (Invitrogen, Karlsruhe, Germany), respectively. Primers 5'GCTGATGACTTCTTCAAGGC-3' and 5'-ATTACATATGCT CCTTTTAT-3' were used for PCR amplification of HvGLP4 from genomic barley DNA (cv. Atlas). Constructs pTaGLP4hairpin and $\mathrm{pH} v \mathrm{GLP} 4$ hairpin were used for hairpin RNAi and contained inverted repeats (IR) of either the TaGLP4 or $H v$ GLP4 genes, separated by the 313-bp second intron of the wheat $R G A 2$ gene (accession no. AF326781). These give rise to dsRNA in vivo with the intron loop between IR1 and IR2 being spliced out. The RNAi expression vector pJP26 was made by cloning the wheat $R G A 2$ intron in $\mathrm{pGY} 1$ between $X b a I$ and SalI sites of the multiple cloning site. Construct pTaGLP4hairpin $\quad\left(35 \mathrm{~S}_{\mathrm{Prom}}-\mathrm{TaGLP}_{\mathrm{IR} 1}-\mathrm{RGA}_{\text {intron }}-\mathrm{TaGLP}_{\mathrm{IR} 2^{-}}\right.$ $35 \mathrm{~S}_{\text {term }}$ ) was obtained by adaptor PCR and cloning of one PCR fragment between the SmaI and XbaI-sites of pJP26 (upstream of the intron), followed by cloning the other fragment between the SpeI and PstI sites of the intermediary product (downstream of the intron). The PCR fragments were obtained from pGLP2 by using primers $5^{\prime}$-ACGTCTTCAAAGCAAGTGG-3' and 5'-GCTCTAGATTCACTCATTACAGACACAA-3' (IR1, ends cut with $S m a \mathrm{I}$ and $X b a \mathrm{I}$ ) or $5^{\prime}$-ACGTCTTCAAAGCAA GTGG-3' and 5'-GGACTAGTTCACTCATTACAGACACA AC-3' (IR2, ends cut with SpeI and PstI). Construct pHvGLP4hairpin $\quad\left(35 \mathrm{~S}_{\text {Prom }}-H \nu \mathrm{GLP} 4_{\mathrm{IR} 1}-\mathrm{RGA} 2_{\text {intron }}-H v \mathrm{GLP} 4_{\mathrm{IR} 2}-35 \mathrm{~S}_{\text {term }}\right)$ was used for hairpin RNAi of HvGLP4 and was obtained by adaptor PCR and cloning of the one PCR fragment between the $B a m \mathrm{HI}$ and $\mathrm{XbaI}$ sites of pJP26 (upstream of intron), followed by cloning the other fragment into the SalI/SphI sites of the intermediary product. The PCR fragments were obtained from pPB-903 by using adapter primers $5^{\prime}$-TTATTAGGATCCATGA CTTCTTCAAGGCAGCC-3' and 5'-TTATTATCTAGAGGAT GCATATCTAGGAAACTC-3' (IR1, sites BamHI and XbaI) or 5'-ATTATTGCATGCATGACTTCTTCAAGGCAGCC- $3^{\prime}$ and 5'-TTATTAGTCGACGGATGCATATCTAGGAAACTC (IR2, sites $S a l \mathrm{I}$ and $S p h \mathrm{I})$. The GFP-fusion construct encoding $H v G L P 4$ fused with GFP (pHvGLP4::GFP) was obtained by in-frame cloning of a $H v G L P 4$ PCR fragment upstream of GFP between the SmaI and BstXI sites of pGermin::GFP (Schweizer et al. 1999a). This replaced Germin gf2.8 with $H v G L P 4$. The HvGLP4 PCR fragment was obtained using primers 5'-TTATTACCCGGGGGAACACAAGACAAGGAA$3^{\prime}$ and $5^{\prime}$-TTATTACCACGACCCTGGTGTGGTTGTTCTCC CAGA-3', followed by cutting of the ends with SmaI and BstXI. The RNAi control constructs pZmA1hairpin and pPrx7hairpin contain inverted repeats of the maize $A 1$ (encoding dihydroflavonol-4-reductase, accession number X05068) and barley $\operatorname{Pr} x 7$ (encoding pathogen-induced vacuolar peroxidase accession number AJ003141 [Kristensen et al 1999) genes, respectively, and were obtained essentially as described for $\mathrm{pH} v \mathrm{GLP} 4$ hairpin.

\section{Protein analyses.}

Crude protein was extracted from leaves of 4-week-old Bastaresistant transgenic lines of $A$. thaliana in $100 \mathrm{mM} \mathrm{CaCl}_{2}(1: 2$, fresh weight plant material/buffer). Ni-NTA affinity purification of the recombinant His-tagged protein was preceded by a heat treatment of $80^{\circ} \mathrm{C}$ for $3 \mathrm{~min}$, followed by a $10,000 \times g$ centrifugation for $5 \mathrm{~min}$ in order to remove heat-unstable proteins. The supernatant was supplied with urea to a final concentration of 8 $\mathrm{M}$ in order to denature $H v$ GLP4 and facilitate proper binding of the His-tag. Four column volumes (CV) of extract was loaded on to a 5-ml Ni-NTA column (Qiagen, Hilden, Germany) at 0.5 $\mathrm{ml} / \mathrm{min}$. Bound protein was washed sequentially with i) $8 \mathrm{M}$ urea in $20 \mathrm{mM}$ Tris, pH 8.0; ii) $8 \mathrm{M}$ urea in $20 \mathrm{mM}$ Tris, $\mathrm{pH} 6.3$; iii) 8 $\mathrm{M}$ urea in $20 \mathrm{mM}$ Tris, pH 8.0, $1 \mathrm{mM} \mathrm{Mn}^{++}$. Bound $H v$ GLP4-CHis was renatured on the column by the removal of urea in a 4 $\mathrm{CV}$ gradient to $20 \mathrm{mM}$ Tris, $\mathrm{pH} 8.0,1 \mathrm{mM} \mathrm{Mn}^{++}$. A final 6-CV wash in $20 \mathrm{mM}$ Tris, $\mathrm{pH} 8.0$, preceded the elution, subsequently performed by adding imidazole to $60 \mathrm{mM}$ into the $20 \mathrm{mM}$ Tris, pH 8.0, buffer.

SDS-PAGE and blotting onto Immobilon-P membranes (Millipore, MA, U.S.A.) were performed according to Sambrook and associates (1989) and Harlow and Lane (1988), respectively. The SDS-resistant $H v$ GLP4 protein was electrophoresed under seminative conditions on standard SDS-PAGE. "Seminative" denotes the fact that the samples are made without reducing agent in the sample buffer and are not boiled prior to loading. Antiserum, raised against denatured HvGLP4 expressed in Escherichia coli (Wei et al. 1998), was used for immunodetection. In order to ascertain recognition of the oligomeric form of $H v$ GLP4 on seminative gel blots, the proteins on these blots were denatured after blotting according to Wei and associates (1998). In-gel assaying for SOD activity was performed according to Beauchamp and Fridovich (1971).

Proteins of barley leaf epidermal and mesophyll tissues were prepared according to Wei and associates (1998). 
Transient gene expression in wheat and barley.

For transient RNAi in wheat, segments of first leaves of 7day-old seedlings were bombarded with DNA- or dsRNA-coated tungsten particles as described (Schweizer et al. 1999b, 2000). For transient overexpression in wheat and for all experiments in barley leaf segments of 7-day-old seedlings were bombarded with gold particles (diameter $1 \mu \mathrm{m}$ ) in a PDS-1000/He system (Bio-Rad, München, Germany), using the hepta adaptor with a helium pressure of 900 psi. The particle coating was done according to Schweizer and associates (1999b), except that the particle supernatant was completely removed after coating and particles were finally resuspended in pure ethanol $(21 \mu$ containing $1,050 \mathrm{mg}$ gold microcarrier per shot). For all experiments in wheat and barley, leaf segments were inoculated with $B$. graminis f. sp. tritici or B. graminis f. sp. hordei $4 \mathrm{~h}$ postbombardment, except for RNAi experiments with the pGLP4 hairpin construct in barley, in which leaf segments were inoculated either 4 or $48 \mathrm{~h}$ postbombardment. For wheat and barley, pUbiGUS containing GUS was used as reporter gene for transformed epidermal cells, and leaf segments were GUS-stained $40 \mathrm{~h}$ postinoculation, followed by staining of epicuticular fungal structures by Coomassie blue R-250 and scoring of interaction phenotypes by light microscopy (Schweizer et al. 1999b). The efficiency of RNAi was tested in barley by cobombarding $\mathrm{pH}$ GLP4::GFP with $\mathrm{pH} v \mathrm{GLP} 4$ hairpin, followed by determination of the number of GFP cells $48 \mathrm{~h}$ later.

\section{Statistics for transient gene expression.}

Frequencies of haustorium formation by $B$. graminis were calculated relative to the corresponding controls (GUS reporter gene plus empty vector or GUS reporter gene plus control RNAi hairpin construct) accompanying each transformation experiment. These relative values were found to be normal distributed $\left(\chi^{2}=2.35\right)$ and could, therefore, be tested for significant difference to the control value $(100 \%)$ by using a onesample $t$-test.

\section{Detection of localized $\mathrm{H}_{2} \mathrm{O}_{2}$ production by DAB-staining.}

$\mathrm{H}_{2} \mathrm{O}_{2}$ was detected in situ by the DAB-uptake method (Thordal-Christensen et al. 1997). Leaves of 7-day-old barley seedlings were bombarded by placing entire seedlings (including root) into the PDS-1000/He system. Bombarded seedlings were grown further in liquid culture for $48 \mathrm{~h}$, followed by inoculation with $B$. graminis f. sp. hordei. Sixteen hours postinoculation, leaves were cut and allowed to take up DAB as described (Thordal-Christensen et al. 1997). Leaves were stained for GUS activity ( $24 \mathrm{~h}$ postinoculation), and absence or presence of detectable DAB-staining in GUS-stained transformed cells was analyzed by light microscopy. Attention was paid to analyze only GUS-stained cells surrounded by cells that showed DAB-staining at sites of attempted penetration.

\section{RNA blot analysis.}

Total RNA was isolated and blotted onto nylon membranes, followed by hybridization with germin probes as described (Vallelian et al. 1998).

\section{ACKNOWLEDGMENTS}

Work was supported by grant number 31-58656.99 of the Swiss National Science Foundation (to R. Dudler), by the Danish National Agricultural and Veterinary Research Council (to A. B. Christensen), and by grant number SCHW-848/1-1 from Deutsche Forschungsgenchschaft and internal funding of the Wilhelm-Gottlieb-Leibniz Society (to P. Schweizer). Excellent technical assistance of J. Schneider, S. Gentz, A. Zander, I. Hansen, and G. Brantin is acknowledged. We thank the "Centre for the Application of Molecular Biology to International Agriculture," Canberra, Australia, for providing the pCAMBIA3301 vector.

\section{LITERATURE CITED}

Alscher, R. G., Erturk, N., and Heath, L. S. 2002. Role of superoxide dismutases (SODs) in controlling oxidative stress in plants. J. Exp. Bot. 53:1331-1341.

Asher, M. J. C., and Thomas, C. E. 1983. The expression of partial resistance to Erysiphe graminis in spring barley. Plant Pathol. 32:79-89.

Azevedo, C., Sadanandom, A., Kitagawa, K., Freialdenhoven, A. Shirasu, K., and Schulze-Lefert, P. 2002. The RAR1 interactor SGT1, an essential component of $R$ gene-triggered disease resistance, Science 295:2073-2076.

Babitha, M. P., Bhat, S. G., Prakash, H. S., and Shetty, H. S. 2002. Differential induction of superoxide dismutase in downy mildew-resistant and -susceptible genotypes of pearl millet. Plant Pathol. 51:480-486

Beauchamp, C., and Fridovich, I. 1971. Superoxide dismutase: Improved assays and an assay applicable to acrylamide gels. Anal. Biochem. 44:276-287.

Bernier, F., and Berna, A. 2001. Germins and germin-like proteins: Plant do-all proteins. But what do they do exactly? Plant Physiol. Biochem. 39:545-554.

Bolwell, G. P., Bindschedler, L. V., Blee, K. A., Butt, V. S., Davies, D. R., Gardner, S. L., Gerrish, C., and Minibayeva, F. 2002. The apoplastic oxidative burst in response to biotic stress in plants: A three-component system, J. Exp. Botany 53:1367-1376.

Carter, C., and Thornburg, R. W. 2000. Tobacco nectarin I. Purification and characterization as a germin-like, manganese superoxide dismutase implicated in the defense of floral reproductive tissues, J. Biol. Chem. 275:36726-33.

Clough, S. J., and Bent, A. F. 1998. Floral dip: A simplified method for Agrobacterium-mediated transformation of Arabidopsis thaliana. Plant J. 16:735-743.

Delledonne, M., Zeier, J., Marocco, A., and Lamb, C. 2001. Signal interactions between nitric oxide and reactive oxygen intermediates in the plant hypersensitive disease resistance response. Proc. Natl. Acad. Sci. U.S.A. 98:13454-13459.

Donaldson, P. A., Anderson, T., Lane, B. G., Davidson, A. L., and Simmonds, D. H. 2001. Soybean plants expressing an active oligomeric oxalate oxidase from the wheat gf- 2.8 (germin) gene are resistant to the oxalate-secreting pathogen Sclerotina sclerotiorum. Physiol. Mol. Plant Pathol. 59:297-307.

Druka, A., Kudrna, D., Kannangara, C. G., von Wettstein, D., and Kleinhofs, A. 2002. Physical and genetic mapping of barley (Hordeum vulgare) germin-like cDNAs. Proc. Natl. Acad. Sci. U.S.A. 99:850-855.

Elliott, C., Zhou, F., Spielmeyer, W., Panstruga, R., and Schulze-Lefert, P. 2002. Functional conservation of wheat and rice Mlo orthologs in defense modulation to the powdery mildew fungus. Mol. Plant-Microbe Interact. 15:1069-1077.

Gay, P. A., and Tuzun, S. 2000. Temporal and spatial assessment of defense responses in resistant and susceptible cabbage varieties during infection with Xanthomonas campestris pv. campestris. Physiol. Mol. Plant Pathol. 57:201-210.

Gregersen, P. L., Thordal-Christensen, H., Förster, H., and Collinge, D. B. 1997. Differential gene transcript accumulation in barley leaf epidermis and mesophyll in response to attack by Blumeria graminis f. sp. hordei (syn. Erysiphe graminis f. sp. hordei). Physiol. Mol. Plant Pathol. 51:85-97.

Harlow E., and Lane D. 1988. Antibodies: A Laboratory Manual. Cold Spring Harbor Laboratory Press, Cold Spring Harbor, NY, U.S.A.

Heath, M. C. 2001. Pathogenicity factors and resistance mechanisms, Physiol. Mol. Plant Pathol. 58:147-148.

Huckelhoven, R., Fodor, J., Preis, C., and Kogel, K. H. 1999. Hypersensitive cell death and papilla formation in barley attacked by the powdery mildew fungus are associated with hydrogen peroxide but not with salicylic acid accumulation. Plant Physiol 119:1251-1260.

Huckelhoven, R., Dechert, C., and Kogel, K. H. 2003. Overexpression of barley BAX inhibitor 1 induces breakdown of mlo-mediated penetration resistance to Blumeria graminis, Proc Natl. Acad. Sci. U.S.A. 100:5555-5560.

Keller, T., Damude, H. G., Werner, D., Doerner, P., Dixon, R. A., and Lamb, C. 1998. A plant homolog of the neutrophil nadph oxidase Gp91(Phox) subunit gene encodes a plasma membrane protein with Ca2+ binding motifs. Plant Cell 10:255-266.

Kim, M. C., Lee, S. H., Kim, J. K., Chun, H. J., Choi, M. S., Chung, W. S., Moon, B. C., Kang, C. H., Park, C. Y., Yoo, J. H., Kang, Y. H., Koo, S. C., Koo, J. D., Jung, J. C., Kim, S. T., Schulze-Lefert, P., Lee, S. Y., and Cho, M. J. 2002. Mlo, a modulator of plant defense and cell death, is a novel calmodulin-binding protein-Isolation and characterization of a rice Mlo homologue, J. Biol. Chem. 277:19304-19314.

Kmecl, A., Mauch, F., Winzeler, M., Winzeler, H., and Dudler, R. 1995. Quantitative field resistance of wheat to powdery mildew and defense 
reactions at the seedling stage: Identification of a potential marker Physiol. Mol. Plant Pathol. 47:185-199.

Kristensen, B. K., Bloch, H., and Rasmussen, S. K. 1999. Barley coleoptile peroxidases. Purification, molecular cloning, and induction by pathogens, Plant Physiol. 120:501-512.

Liang, H., Maynard, C. A., Allen, R. D., and Powell, W. A. 2001. Increased Septoria musiva resistance in transgenic hybrid poplar leaves expressing a wheat oxalate oxidase gene. Plant Mol. Biol. 45:619-29.

Mellersh, D. G., Foulds, I. V., Higgins, V. J., and Heath, M. C. 2002. $\mathrm{H}_{2} \mathrm{O}_{2}$ plays different roles in determining penetration failure in three diverse plant-fungal interactions. Plant J. 29:257-268.

Nielsen, K., Olsen, O., and Oliver, R. 1999. A transient expression system to assay putative antifungal genes on powdery mildew infected barley leaves. Physiol. Mol. Plant Pathol. 54:1-12.

Ramputh, A. I., Arnason, J. T., Cass, L., and Simmonds, J. A. 2002. Reduced herbivory of the European corn borer (Ostrinia nubilalis) on corn transformed with germin, a wheat oxalate oxidase gene. Plant Sci. 162:431-440.

Rodriguez-Lopez, M., Baroja-Fernandez, E., Zandueta-Criado, A., Moreno-Bruna, B., Munoz, F. J., Akazawa, T., and Pozueta-Romero, J. 2001. Two isoforms of a nucleotide-sugar pyrophosphatase/phosphodiesterase from barley leaves (Hordeum vulgare L.) are distinct oligomers of $H v$ GLP1, a germin-like protein. FEBS (Fed. Eur. Biochem. Soc.) Lett. 490:44-48

Sagi, M., and Fluhr, R. 2001. Superoxide production by plant homologues of the gp91(phox) NADPH oxidase. Modulation of activity by calcium and by tobacco mosaic virus infection. Plant Physiol. 126:1281-90.

Sambrook, J., Fritsch, E. F., and Maniatis, T. 1989. Molecular Cloning: A Laboratory Manual. Cold Spring Harbor Laboratory Press, Cold Spring Harbor, NY, U.S.A.

Schulze-Lefert, P., and Vogel, J. 2000. Closing the ranks to attack by powdery mildew. Trends Plant Sci. 5:343-348.

Schweizer, P., Hunziker, W., and Mosinger, E. 1989. Complementary DNA cloning In vitro,transcription, and partial sequence analysis of messenger RNA from winter wheat Triticum aestivum L. with induced resistance to Erysiphe graminis f. sp. tritici. Plant Mol. Biol. 12:643-654.

Schweizer, P., Christoffel, A., and Dudler, R. 1999a. Transient expression of members of the germin-like gene family in epidermal cells of wheat confers disease resistance. Plant J. 20:541-552.

Schweizer, P., Pokorny, J., Abderhalden, O., and Dudler, R. 1999b. A transient assay system for the functional assessment of defense-related genes in wheat. Mol. Plant-Microbe Interact. 12:647-654.

Schweizer, P., Pokorny, J., Schulze-Lefert, P., and Dudler, R. 2000. Technical Advance: Double-stranded RNA interferes with gene function at the single-cell level in cereals. Plant J. 24:895-903.

Segarra, C. I., Casalongue, C. A., Pinedo, M. L., Ronchi, V. P., and Conde, R. D. 2003. A germin-like protein of wheat leaf apoplast inhibits serine proteases, J. Exp. Bot. 54:1335-1341.

Thordal-Christensen, H., Gregersen, P. L., and Collinge, D. B. 2000. The barley/Blumeria (syn. Erysiphe) graminis interaction: A case study. Pages 77-100 in: Mechanisms of Resistance to Plant Diseases. A. Slusarenko, R. Fraser, and K. van Loon, eds. Kluwer Academic Publishers, Dordrecht, The Netherlands.

Thordal-Christensen, H., Zhang, Z., Wei, Y., and Collinge, D. B. 1997. Subcellular localization of $\mathrm{H}_{2} \mathrm{O}_{2}$ in plants. $\mathrm{H}_{2} \mathrm{O}_{2}$ accumulation in papillae and hypersensitive response during the barley-powdery mildew interaction. Plant J. 11:1187-1194.

Vallelian, B. L., Mosinger, E., Metraux, J. P., and Schweizer, P. 1998. Structure, expression and localization of a germin-like protein in barley (Hordeum vulgare L.) that is insolubilized in stressed leaves. Plant Mol. Biol. 37:297-308.

Wei, Y. D., Zhang, Z. G., Andersen, C. H., Schmelzer, E., Gregersen, P. L., Collinge, D. B., Smedegaard-Petersen, V., and Thordal-Christensen, H. 1998. An epidermis/papilla-specific oxalate oxidase-like protein in the defense response of barley attacked by the powdery mildew fungus. Plant Mol. Biol. 36:101-112.

Woo, E. J., Dunwell, J. M., Goodenough, P. W., Marvier, A. C., and Pickersgill, R. W. 2000. Germin is a manganese containing homohexamer with oxalate oxidase and superoxide dismutase activities. Nature Struct. Biol. 7:1036-1040.

Yamahara, T., Shiono, T., Suzuki, T., Tanaka, K., Takio, S., Sato, K., Yamazaki, S., and Satoh, T. 1999. Isolation of a germin-like protein with manganese superoxide dismutase activity from cells of a moss, Barbula unguiculata. J. Biol. Chem. 274:33274-33278.

Yoshioka, H., Sugie, K., Park, H.-J., Maeda, H., Tsuda, N., Kawakita, K., and Doke, N. 2001. Induction of plant gp91 phox homolog by fungal cell wall, arachidonic acid, and salicylic acid in potato. Mol. PlantMicrobe Interact. 14:725-736.

Zhou, F., Kurth, J., Wei, F., Elliott, C., Vale, G., Yahiaoui, N., Keller, B. Somerville, S., Wise, R., and Schulze-Lefert, P. 2001. Cell-autonomous expression of barley Mlal confers race-specific resistance to the powdery mildew fungus via a Rar1-independent signaling pathway. Plant Cell 13:337-350.

\section{AUTHOR-RECOMMENDED INTERNET RESOURCE}

The Institute of Plant Genetics (IPK) Crop EST database: pgrc.ipkgatersleben.de/cr-est/login.php 